\title{
CONSTRUÇÃo DE UMA CELA DE FLUXO PARA MEDIDAS POR ESPECTROFOTOMETRIA EM FASE SÓLIDA
}

Boaventura F. Reis

Centro de Energia Nuclear na Agricultura - Universidade de São Paulo - CP 96 - 13400-970 - Piracicaba - SP

Fábio R. P. Rocha

Departamento de Química - Universidade Federal de São Carlos - CP 676 - 13565-905 - São Carlos - SP

Leonardo Sena Gomes Teixeira, Antônio Celso Spinola Costa

Instituto de Química - Universidade Federal da Bahia - Campus Universitário de Ondina - 40170-290 - Salvador - BA

Mauro Korn

Departamento de Ciências Exatas e da Terra - Universidade do Estado da Bahia - Campus I - 41195-001 - Salvador - BA

Recebido em 13/1/99; aceito em 23/4/99

\begin{abstract}
CONSTRUCTION OF A FLOW CELL FOR MEASUREMENTS BY SOLID-PHASE SPECTROPHOTOMETRY. A simple and low cost flow cell is proposed for measurements by solid-phase spectrophotometry employing a conventional spectrophotometer. The flow cell geometry allows the employment of a large amount of the solid support without causing both excessive attenuation of the radiation beam and increasing of the back-pressure. The adaptation of the flow cell in the optical path of the spectrophotometer in order to increase the precision is discussed. The flow cell characteristics were demonstrated by measurements of Co(II), employing 1-(2-tiazolylazo)-2-naphthol (TAN) immobilized on $\mathrm{C}_{18}$ bonded silica as solid support. The apparent molar absorptivity and coefficient of variation were estimated as $1.86 \times 10^{5} \mathrm{~L} \mathrm{~mol}^{-1} \mathrm{~cm}^{-1}$ and $1.4 \%(\mathrm{n}=15)$. A sample throughput of 40 determinations per hour and a detection limit of $15 \mu \mathrm{g} \mathrm{L}^{-1}(99.7 \%$ confidence level) were achieved.
\end{abstract}

Keywords: flow cell; solid-phase spectrophotometry; flow analysis.

\section{INTRODUÇÃO}

O uso da espectrofotometria em fase sólida (EFS) vem crescendo devido à simplicidade, facilidade de automação e baixos limites de detecção que podem ser alcançados ${ }^{1}$. Nesta técnica, uma matriz sólida depositada na cela de medida é utilizada para a retenção da espécie de interesse, sendo a absorvância medida diretamente no suporte sólido ${ }^{2}$. A concentração in situ do analito é possível devido à acumulação desta espécie em um pequeno volume da fase sólida. Essas características são evidenciadas pelo acoplamento da EFS com sistemas de análise em fluxo (FI-EFS) ${ }^{3}$. Neste caso, um aumento de seletividade pode ser alcançado devido às diferenças na cinética de retenção do analito e das espécies concomitantes no suporte sólido ${ }^{1,4,5}$.

Em procedimentos envolvendo EFS, o feixe incidente sofre tanto absorção quanto espalhamento de radiação ${ }^{6}$. Estes dois fatores contribuem para a atenuação da radiação que atinge o detector, o que diferencia a EFS da espectrofotometria convencional, na qual a atenuação ocorre principalmente devido aos processos de absorção. O espalhamento de radiação na cela que contém a fase sólida é a principal desvantagem da EFS, pois aumenta significativamente os desvios nas medidas. Entretanto, essa limitação vem sendo superada pelo emprego de lentes para a dispersão da radiação incidente, ou pelo posicionamento da cela próximo à entrada do sistema de detecção $0^{3,6,7}$.

Para medidas em fluxo por espectrofotometria em fase sólida têm sido empregadas celas comerciais ${ }^{8-10}$ ou especialmente construídas para FI-EFS ${ }^{4,11}$. Entretanto, celas de fluxo disponíveis comercialmente apresentam limitações na quantidade de sólido que pode ser utilizada, podendo comprometer a sensibilidade e a faixa de resposta. O emprego de uma quantidade excessiva do suporte sólido torna crítico o espalhamento de radiação, além de aumentar a impedância hidrodinâmica do sistema. Neste trabalho, é proposta a construção e adaptação de uma cela de fluxo simples e de baixo custo para medidas por FI-EFS, que permite a utilização de maiores quantidades de material sem ocasionar excessivo aumento da impedância hidrodinâmica e do espalhamento de radiação. A reação de cobalto(II) com 1-(2-tiazolilazo)-2-naftol (TAN) imobilizado em silica funcionalizada $\mathrm{C}_{18}$ foi utilizada para demonstrar as características da cela de fluxos proposta.

\section{PARTE EXPERIMENTAL}

\section{Reagentes e soluções}

Todas as soluções foram preparadas empregando água destilada e deionizada e reagentes de grau analítico. Sílica funcionalizada $C_{18}(60-100 \mathrm{~mm})$ obtida a partir de colunas SepPak (Waters) foi utilizada para imobilização do reagente cromogênico. Papel fotossensível foi usado nas medidas de área do feixe luminoso.

- Soluções de cobalto contendo 0,25 - 5,0 mg $\mathrm{L}^{-1}$ foram preparadas em tampão hexamina $\left(0,125 \mathrm{~mol} \mathrm{~L}^{-1}, \mathrm{pH} 6,0\right)$ por diluições apropriadas de uma solução estoque 1000 $\mathrm{mg} \mathrm{L}^{-1}$ preparada por dissolução de cobalto metálico em ácido nítrico.

- Solução de 1-(2-tiazolilazo)-2-naftol (TAN) 0,03\% (m/v), preparada por dissolução de $0,03 \mathrm{~g}$ de TAN em $5 \mathrm{~mL}$ de etanol e diluição para $100 \mathrm{~mL}$ com uma solução $1 \%(\mathrm{~m} / \mathrm{v})$ de triton X-100.

Solução $0,5 \mathrm{~mol} \mathrm{~L}^{-1} \mathrm{HCl}$.

- Solução para revelação das fotografias: solução aquosa contendo $0,3 \%(\mathrm{~m} / \mathrm{v})$ sulfato de monometil p-aminofenol; $4,5 \%$ $(\mathrm{m} / \mathrm{v})$ sulfito de sódio; $1,2 \%(\mathrm{~m} / \mathrm{v})$ hidroquinona; $8,0 \%(\mathrm{~m} /$ v) carbonato de sódio; $0,2 \%(\mathrm{~m} / \mathrm{v})$ brometo de potássio.

- Solução para fixação das fotografias: solução aquosa contendo $24 \%(\mathrm{~m} / \mathrm{v})$ hipossulfito de sódio; $1,5 \%(\mathrm{~m} / \mathrm{v})$ sulfito de sódio; $1,4 \%(\mathrm{~m} / \mathrm{v})$ ácido acético; $0,75 \%(\mathrm{~m} / \mathrm{v})$ ácido bórico; $1,5 \%(\mathrm{~m} / \mathrm{v})$ sulfato de potássio e alumínio. 


\section{Equipamentos}

As medidas de absorvância foram feitas utilizando um espectrofotômetro Cary 1E (Varian), no qual foi adaptada a cela de fluxo descrita a seguir. A propulsão dos fluidos foi efetuada por uma bomba peristáltica Reglo (Ismatec) equipada com tubos de Tygon. Para a inserção das soluções (amostra e eluente) foi empregado um injetor proporcional de barra deslizante. Medidas em solução foram feitas empregando a cela de fluxos sem a deposição do suporte sólido, bem como uma cela comercial (Hellma) de $80 \mu \mathrm{L}$ com $10 \mathrm{~mm}$ de caminho óptico.

\section{Descrição da cela de fluxo}

A cela de fluxos (Fig. 1) consiste de dois blocos de acrílico (A) separados por uma tira de borracha (B) de $1 \mathrm{~mm}$ de espessura, na qual é feito um corte circular com $10 \mathrm{~mm}$ de diâmetro (C). Um dos blocos de acrílico possui dois furos transversais $(0,8 \mathrm{~mm})$, distantes $9 \mathrm{~mm}$ entre si, empregados para a entrada (E) e saída (D) dos fluidos. A tira de borracha é presa entre os blocos através de quatro parafusos, de forma a evitar vazamentos. O corte circular (C) define o espaço no qual é depositado o suporte sólido. Lã de vidro é utilizada para evitar o arraste do material sólido pela passagem dos fluidos. A tira de borracha é posicionada de forma que o corte circular coincida com a entrada e saída dos fluidos, definindo a posição de incidência do feixe de radiação.
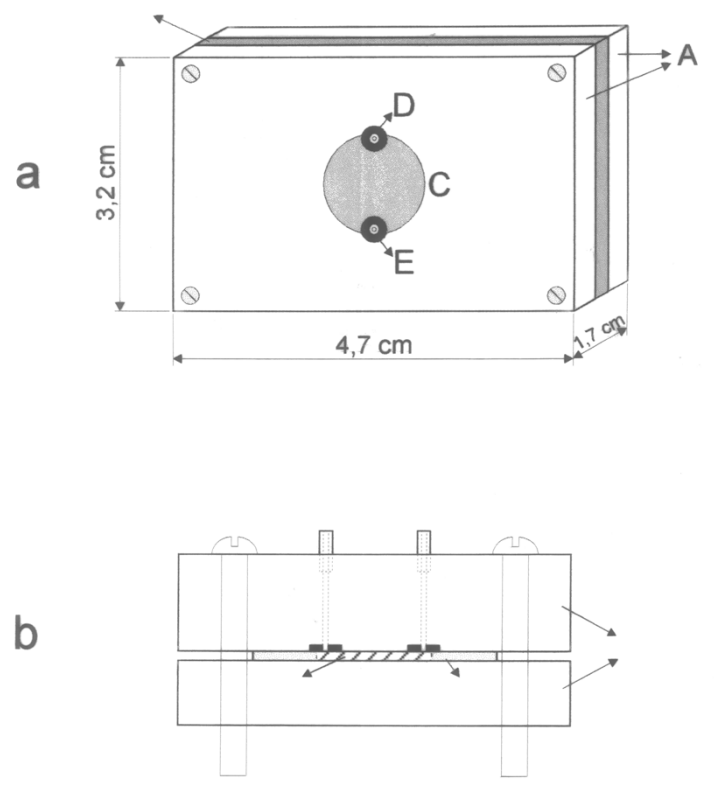

Figura 1. Representação esquemática da cela de fluxos para FI-EFS. (a) Vista frontal e (b) Vista em corte. A - blocos de acrílico; B - tira de borracha (1 mm de espessura); $C$ - corte circular $(10 \mathrm{~mm}$ de diâmetro) que define o espaço onde é depositado o suporte sólido; D saída de fluido; E - entrada de fluido.

A cela de fluxos é preenchida com ca. $35 \mathrm{mg}$ de sílica funcionalizada $\mathrm{C}_{18}$ e a imobilização do reagente cromogênico por adsorção no suporte é feita pela passagem da solução de TAN pela cela por 2 min a $1,5 \mathrm{~mL} \mathrm{~min}^{-1}$. Posteriormente, a cela é lavada com a solução de $\mathrm{HCl}$ e água deionizada.

\section{Diagrama de fluxos e procedimento}

O diagrama de fluxos empregado é mostrado na Fig. 2. O módulo de análise permite a inserção simultânea de alíquotas de amostra e eluente $(\mathrm{HCl})$ no fluido transportador $\left(\mathrm{H}_{2} \mathrm{O}\right)$. Uma bobina (B) é empregada para permitir a defasagem temporal entre a chegada da amostra e do eluente na cela de fluxos. O analito é retido na fase sólida devido à formação de um complexo com TAN, sendo posteriormente eluido pela solução ácida. Simultaneamente, medidas de absorvância na fase sólida são efetuadas em $572 \mathrm{~nm}$.

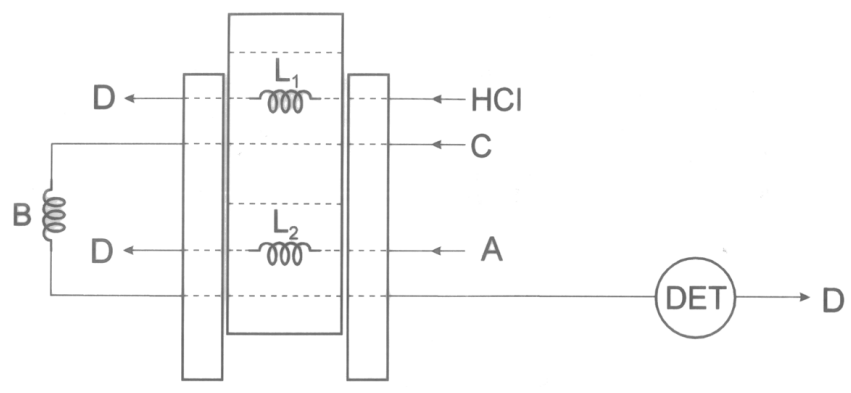

Figura 2. Diagrama de fluxos do módulo de análise para medidas de cobalto(II) por FI-EFS. A - amostra (625 ou $1250 \mu \mathrm{L})$; C - transportador $\left(\mathrm{H}_{2} \mathrm{O}\right) ; L_{1}, L_{2}$ - alças de amostragem; $B$ - bobina de dispersão $(80 \mathrm{~cm}) ; \mathrm{D}$ - descarte de soluções; DET - cela de fluxos contendo o suporte sólido inserida no caminho óptico do espectrofotômetro. Uma solução $0,5 \mathrm{~mol} \mathrm{~L}^{-1} \mathrm{HCl}(400 \mu \mathrm{L})$ foi empregada como eluente. A vazão do transportador foi mantida em 1,5 $\mathrm{mL} \mathrm{min}^{-1}$.

Para efeito de comparação, medidas de absorvância em solução foram feitas empregando um sistema similar (Fig. 2), com a introdução do reagente cromogênico por confluência $(0,5$ $\mathrm{mL} \min ^{-1}$ ), reduzindo a vazão do transportador de forma a manter a vazão total em $1,5 \mathrm{~mL} \mathrm{~min}^{-1}$.

As medidas da área do feixe luminoso em função do posicionamento da cela no compartimento do espectrofotômetro foram feitas pela exposição de tiras de papel fotográfico ${ }^{12}$ ao feixe de radiação $(400 \mathrm{~nm})$ por $30 \mathrm{~s}$, com posterior revelação e fixação.

\section{RESULTADOS E DISCUSSÃO}

A cela de fluxos proposta apresenta $78 \mathrm{~mm}^{2}$ de seção transversal e caminho óptico de $1 \mathrm{~mm}$ (volume $=78 \mu \mathrm{L}$ ). Este dimensionamento permite a utilização de uma maior quantidade de suporte sólido, em relação às celas comerciais, sem ocasionar atenuação excessiva do feixe de radiação incidente. $\mathrm{O}$ emprego de maiores quantidades de material possibilita o aumento do número de sítios de adsorção, ampliando a sensibilidade e a faixa de resposta. Outra característica resultante da geometria da cela é a distribuição do fluido por uma maior área, minimizando a possibilidade de vazamentos causados pelo aumento da impedância hidrodinâmica do sistema ocasionada pelo material sólido.

A geometria da cela pode provocar uma distribuição não homogênea do analito, devido à ocorrência de caminhos preferenciais. Desta forma, a precisão das medidas pode ser comprometida caso a cela de fluxos seja posicionada no foco do feixe de radiação, devido à incidência de radiação em uma área limitada do suporte sólido. Este inconveniente pode ser superado, afastando a cela do foco e posicionando-a próxima à entrada do sistema de detecção, permitindo que uma maior área da fase sólida seja iluminada. Para o sistema $\mathrm{Co}(\mathrm{II}) / \mathrm{C}_{18} / \mathrm{TAN}$, o coeficiente de variação das medidas de absorvância em função da área do suporte sólido iluminada pelo feixe de radiação é mostrado na Tabela 1 . Um compromisso entre a precisão das medidas e a magnitude do sinal deve ser observado para o estabelecimento da área iluminada, ou seja, o posicionamento da cela no gabinete do espectrofotômetro ${ }^{7}$. As medidas da área iluminada pelo feixe de radiação em função do posicionamento da cela no compartimento do espectrofotômetro foram feitas através das fotografias mostradas na Figura 3. 
Tabela 1. Efeito do posicionamento da cela no espectrofotômetro. Sinais obtidos para $1 \mathrm{mg} \mathrm{L}^{-1} \mathrm{Co}(\mathrm{II})$ em tampão hexamina, pH 6,5.

\begin{tabular}{lccc}
\hline Posição $^{\mathrm{a}}$ & $\begin{array}{c}\text { Área do feixe } \\
\text { incidente }{ }^{\mathrm{b}} / \mathrm{cm}^{2}\end{array}$ & Absorvância & $\mathrm{CV}(\%)^{\mathrm{c}}$ \\
\hline$-6,0$ (monocromador) & 0,77 & 0,426 & 2,1 \\
$-4,5$ & 0,48 & 0,428 & 2,8 \\
$-2,5$ & 0,32 & 0,454 & 3,7 \\
0 (foco) & 0,20 & 0,532 & 5,6 \\
2,5 & 0,32 & 0,446 & 3,9 \\
4,5 & 0,48 & 0,424 & 2,6 \\
6,0 (detector) & 0,77 & 0,412 & 1,2 \\
\hline
\end{tabular}

a. Posição da cela em relação ao foco (distâncias em $\mathrm{cm}$ )

b. Determinadas através das fotografias mostradas na Fig. 3.

c. Coeficiente de variação das medidas $(n=10)$

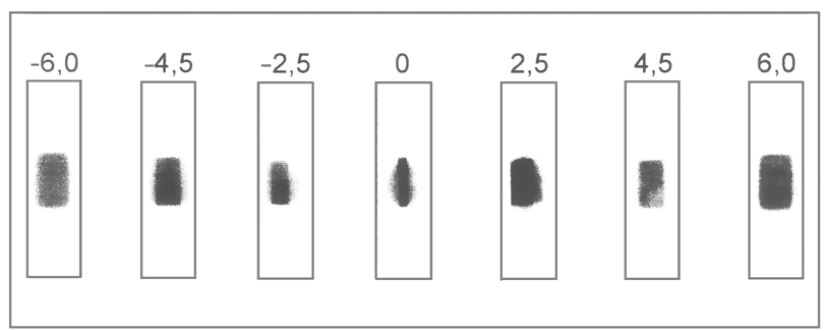

Figura 3. Fotografias utilizadas para a medida de área do feixe incidente em função do posicionamento da cela. Os números indicam a distância em $\mathrm{cm}$ da posição de foco do feixe incidente. Números negativos indicam que a cela foi posicionada próximo ao monocromador.

Uma das principais vantagens da espectrofotometria em fase sólida é o aumento de sensibilidade em relação à obtida através de medidas em solução. Sinais obtidos com o sistema FI-EFS foram comparados com os obtidos em um sistema FIA com a introdução de reagente por confluência, empregando a cela de fluxo para FI-EFS sem a deposição do suporte sólido ou uma cela de fluxo comercial $(80 \mu \mathrm{L})$ com $10 \mathrm{~mm}$ de caminho óptico (Fig. 4). A espectrofotometria em fase sólida permitiu um aumento de sensibilidade em relação à obtida em solução, mesmo quando uma cela com caminho ótico 10 vezes maior foi empregada. Além disso, as medidas em solução foram feitas em condição de dispersão limitada, sendo pouco significativa a variação de sensibilidade quando o volume de amostra foi aumentado de 625 para $1250 \mu \mathrm{L}$. Nas mesmas condições, um aumento de sensibilidade de $33 \%$ foi observado para medidas por FI-EFS, devido à concentração do analito (Fig. 4b). Outra vantagem da FI-EFS é o reduzido consumo de reagentes. A imobilização de TAN em sílica funcionalizada permitiu que mais de 200 medidas fossem efetuadas, sem significativa variação de sensibilidade. Nestas condições, o consumo do reagente cromogênico foi inferior a $1 \mathrm{mg}$ por determinação ${ }^{3}$.

Os registros dos sinais transientes obtidos para soluções contendo de 0,25 a $2,0 \mathrm{mg} \mathrm{L}^{-1}$ de cobalto e no estudo de repetibilidade para uma solução $0,5 \mathrm{mg} \mathrm{L}^{-1} \mathrm{Co}$ (II) são mostrados na Fig. 5. As medidas são caracterizadas por boa estabilidade da linha base e repetibilidade (coeficiente de variação estimado em 1,4\%). Para soluções contendo de 0,25 a $3,0 \mathrm{mg}$ $\mathrm{L}^{-1} \mathrm{Co}(\mathrm{II})$, a correlação entre absorvância e concentração do analito é descrita pela equação: $A=0,0386+0,316 C(r=$ 0,9994). A absortividade molar e o limite de detecção foram estimados em $1,86 \times 10^{5} \mathrm{~L} \mathrm{~mol}^{-1} \mathrm{~cm}^{-1}$ e $15 \mathrm{mg} \mathrm{L}^{-1}$ (nível de confiança de $99,7 \%$ ). A frequência de amostragem foi estimada em 40 medidas/h.

Embora o desempenho alcançado em medidas por FI-EFS seja

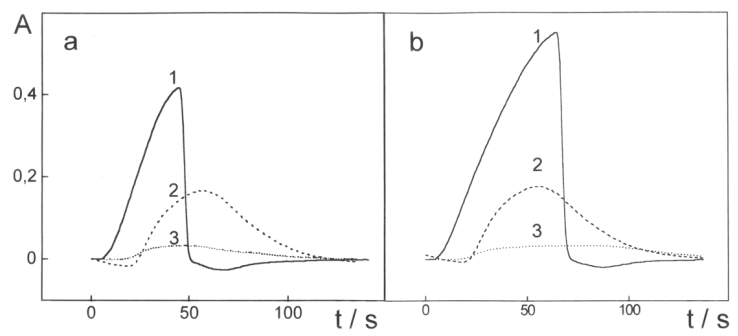

Figura 4. Sinais transientes para $1 \mathrm{mg} \mathrm{L}^{-1} \mathrm{Co}(\mathrm{II})$, empregando a cela de fluxos para FI-EFS com (1) e sem o suporte sólido (3). O sinal 2 foi obtido com um cela comercial com volume similar e $10 \mathrm{~mm}$ de caminho óptico. (a) Volume de amostra $=625 \mu \mathrm{L} e(b)$ volume de amostra $=1250 \mu \mathrm{L}$.

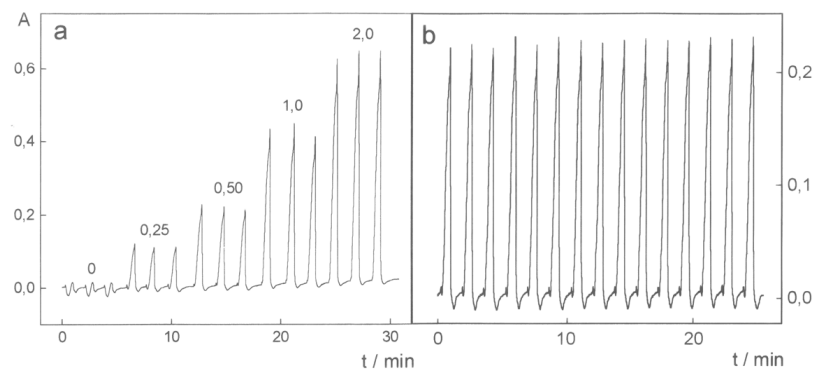

Figura 5. Sinais transientes obtidos para soluções de Co(II) empregando FI-EFS. Em a, os números indicam as concentrações de cobalto em $m g L^{-1}$. No estudo de reptibilidade (b), foi empregada uma solução $0,5 \mathrm{mg} \mathrm{L}^{-1} \mathrm{Co}(\mathrm{II})$. Volume de amostra $=625 \mu \mathrm{L}$.

dependente do sistema químico (tipo de suporte, reagente imobilizado, eluente empregado etc), as caraterísticas e a adaptação da cela proposta no compartimento do espectrofotômetro são fatores importantes para o sucesso de uma aplicação em FI-EFS.

\section{AGRADECIMENTOS}

Os autores agradem ao Prof. Miguel Fascio pela ajuda na obtenção das fotografias e ao CNPq, CAPES, FAPESP e FINEP pelo apoio financeiro.

\section{REFERÊNCIAS}

1. Lobinski, R.; Marczenko, Z.; Crit. Rev. in Anal. Chem. 1992, 23, 55.

2. Pascual-Reguera, M. I.; Molina-Diaz, A.; Ramos-Martos, N.; Anal. Lett. 1991, 24, 2245.

3. Teixeira, L. S. G.; Rocha, F. R. P.; Korn. M.; Reis. B. F.; Ferreira, S. L. C.; Costa, A. C. S.; Anal. Chim. Acta 1999, 383, 307.

4. Lacy, N.; Christian, G. D.; Ruzicka, J.; Anal. Chem. 1990, 62, 1482 .

5. Yoshimura, K.; Analyst 1988, 113, 471.

6. Yoshimura, K.; Waki, H.; Talanta 1985, 32, 345.

7. Brykina, G. D.; Marchenko, D. Y.; Shpigun, O. A.; J. Anal. Chem. 1995, 50, 440.

8. Yoshimura, K.; Anal. Chem. 1987, 59, 2922.

9. Fernández-Band, B.; Lázaro, F.; Luque de Castro, M. D.; Anal. Chim. Acta 1990, 229, 177.

10. Capitan-Vallvey, L. F.; Valencia, M. C.; Mirón, G.; Anal. Chim. Acta 1994, 289, 365.

11. Linares, P.; Luque de Castro, M. D.; Valcárcel, M.; Anal. Chim. Acta 1990, 230, 199.

12. Rains, S. D.; Anal. Chem. 1978, 50, 680. 